\title{
UTOPIA DO BEM SEGUNDO O PAPA FRANCISCO
}

Bárbara P. Bucker ${ }^{1}$

Quando se fala de 'utopia' não raro pensa-se em idealizações que nunca chegam a se concretizar. No entanto, é necessário considerar que é justamente sob no impulso da utopia, que se pode conhecer a força que delineia uma sociedade ideal, fundamentada em leis justas e em instituições sociais político-econômicas e educacionais, verdadeiramente comprometidas com o bem-estar da coletividade; tudo isso como exigência de compromisso pessoal e da formação da consciência bem fundamentadas nos valores; na liberdade do sujeito; nas relações de reconhecimento da dignidade de todo ser humano, e na busca de coerência por uma conduta humana e humanizadora.

Segundo os dados do site da Santa Sé, dia 19 de março de 2018 celebramos o quinto aniversário do pontificado do Papa Francisco, conhecido por alguns como o 'reformador católico do século XXl' e 'profeta pastor que denuncia a injustiça e promove a conversão'. ${ }^{2}$ Também neste século se vive a necessidade de testemunhos no cuidado e atenção pela qualidade de vida de uma grande maioria de seres humanos que vivem extrema solidão e isolamento humano, deixando mais evidente estes sofrimentos, no atual contexto da chamada 'revolução da comunicação' e dos avanços da moderna tecnologia.

O Papa vem insistindo em várias oportunidades sobre a necessidade de superação da indiferença, e ao dirigir-se aos bispos por ocasião da jornada mundial dos pobres, manifesta o desejo de que: "em todo o mundo as comunidades cristãs se convertam cada vez mais e melhor em sinal concreto do amor de Cristo pelos últimos e os mais necessitados", ${ }^{3}$ tornando possível o exercício do 'ministério da aproximação' entre os humanos e o cuidado pela natureza.

São inúmeras às vezes, em que vem afirmando o foco articulador do cuidado prioritário aos migrantes, refugiados e abandonados, fazendo que sua voz ecoe em favor dos sujeitos nas periferias do planeta, e insistindo na misericórdia e alegria como um modo de ação da primavera franciscana, e um contínuo convite para a irmandade.

Percebe-se que a motivação primeira de seu pontificado é a missão, e não mais a conservação, ou um serviço narcisista da Igreja de Jesus Cristo olhando para si mesma. Podemos dizer que, é tempo oportuno do exercício de uma 'Igreja em saída', ${ }^{4}$ sendo assim ela fiel à sua identidade missionária e esponsal, que advém de um discipulado segundo os passos e intuições programáticas do Concílio Vaticano II.

O Papa chama nossa atenção para a crise que vivemos no presente, global e complexa, desejando que se torne concreta a ideia de um mundo sem fronteiras. Interroga-nos constantemente sobre as escolhas feitas até o momento presente, e sobre o rumo que

\footnotetext{
1 Teóloga, professora do Departamento de Teologia, setor Cultura Religiosa.

2 Prólogo de Juan Carlos Scannone ao livro de Emile Cuda: "Para leer a Francisco". Manantial, Buenos Aires, p. 15.

${ }^{3}$ Papa Francisco, Mensagem I Jornada Mundial dos pobres, 6.

${ }^{4}$ Evangelii Gaudium, 20.
} 
tencionamos seguir no futuro, chamando à responsabilidade pessoas e instituições no trabalho de eliminar as barreiras que legitimam desigualdades, subdesenvolvimento, violação dos direitos fundamentais, discriminações, e impedimentos à vida social, cultural e religiosa.

Isto exige uma reflexão realista, não apenas sobre o nosso pequeno mundo quotidiano pessoal, mas também sobre a natureza dos vínculos que unem as comunidades; que em nosso caso é acadêmico, para que esta faça juz ao compromisso e testemunho institucional como Pontifícia e Católica em seu interior. Considerando que este trabalho deverá fazer-se realidade em nós mesmos como seres humanos em movimento, nos muitos afazeres como professores, alunos e funcionários dos diversos setores que a compõem, e formando na prática uma obra em contínua construção, que inclui lugar e tempo em que se encarna a história de cada um, mulheres e homens, comunidades e povos situados neste determinado espaço geográfico.

Por conseguinte, o aspecto ético a ser considerado é exigência contínua de repensar ações e propor condutas de serviço, e não um tipo de atividade de propaganda, que torna o ser humano refém de interesses particulares, e que pode gerar conflitos no confronto com a autenticidade das variadas maneiras de pensar, trazendo como consequência uma amarga situação de isolamento de uns, que faz a todos mais pobres da riqueza que advém dos demais nas variadas relações.

Com um 'olhar reflexivo', diria até contemplativo em meio às inúmeras crises que existe de convicções, valores e decisões; este tempo também pode oferecer uma oportunidade renovada e desafiadora de concorrer para estabelecer no diverso, novas relações verdadeiramente justas e solidárias, pelas quais cada grupo humano seja respeitado na sua identidade e dignidade, bem como promovidos em sua liberdade. Deste modo, os profissionais do presente e do futuro nas variadas áreas do saber e da ciência, terão a possibilidade de discernir e decidir as muitas maneiras de realizar suas aspirações como criaturas, feitas à imagem do Criador.

A verdadeira utopia do bem não é uma ideologia nem uma filantropia, mas um modo positivo de expressar e consolidar a fraternidade presente nas raízes da realização da família humana, de modo que esta possa ser chamada e motivada a crescer e a propagar-se produzindo seus frutos em qualquer lugar e nas diversas situações da vida, adverte-nos o Papa em seus inúmeros discursos e alocuções. ${ }^{5}$

O 'ministério acadêmico' de uma instituição cristã católica, é abrangente em suas diversas atividades, e a preocupação pela formação e colaboração de futuros profissionais, assim como daqueles que já estão em ação no presente, deve manter e sustentar a necessidade de renovação permanente de mentalidade, que a teologia chama de 'conversão ou metanoia' como um 'ethos' que garante a transformação do ser humano pessoal. Diz-nos com acerto Tomás Halík \begin{tabular}{lrcr}
\hline 5 & Cf. & Disponível em discursos:<http://w2.vatican.va/.../pt/speeches/2014/may/documents/papa-
\end{tabular} 
que, "num mundo hominizado, mas não humanizado, as pessoas se sentem perdidas". ${ }^{6}$ Devese manter em geral, uma atenção renovada para as condutas que sirvam de freio para a lógica do individualismo, da competição e do desejo de ser o mais importante; modos que elucidam o proceder de uma 'ética da solidariedade' (cf. João Paulo II, Sollicitudo rei socialis, 38), para substituir a dinâmica de quem pode mais e tem mais poder, justificando assim os esforços e empreendimentos no dinamismo e desempenho das muitas vidas comprometidas com um serviço acadêmico consciente.

O Papa Francisco afirma que é a partir da "abertura à transcendência que poderia formarse uma nova mentalidade política, empresarial, sócio educacional, capaz de guiar ações econômicas e financeiras na ótica de uma ética verdadeiramente humana, e contar com pessoas de grande honestidade e integridade pessoal, cujo trabalho é inspirado e guiado por elevados ideais de justiça, generosidade e solicitude pelo autêntico desenvolvimento da família humana", e exorta a enfrentar este desafio com determinação, sem ignorar a especificidade científica e profissional de cada contexto, de modo que a riqueza material esteja a serviço da humanidade. 7

$\mathrm{Na}$ visão de Francisco, sejam quais forem os poderes instituídos, é preciso cuidar para que o direito e o respeito, como tantos outros valores que tecem a vida humana não sejam substituídos pelo bezerro de ouro. "Vemos que a adoração do antigo bezerro de ouro (cf. Ex 32,18) encontrou uma nova e cruel versão na idolatria do dinheiro e na ditadura de uma economia realmente sem fisionomia nem finalidade humanas". ${ }^{8}$ É no exercício da reflexão que verificamos nossa aquisição de 'conhecimento reflexivo' que nos faz ver como num 'espelho' de constatação, a possibilidade de novas decisões éticas, intuindo o rumo que vão tomar as relações, vinculadas à imagem que cada um tem da pessoa humana, de povos, e do Estado.

A perspectiva da ética cristã deve avaliar tanto o que é autenticamente humano como aquilo que deriva da liberdade da pessoa em sua abertura ao novo, e do seu espírito que une a dimensão humana à dimensão transcendente. Se o ser humano manifesta a riqueza de sua humanidade na comunicação, no relacionamento e no amor pelos seus semelhantes, será possível gerar convicções e práticas docentes bem arraigadas aos valores, porque o serviço que prestam as instituições cristãs consiste em dar atenção diante das necessidades dos seres humanos, descobrindo precisamente as capacidades e as carências que existem. Trata-se de rejeitar a indiferença, fruto do egoísmo utilitarista para fazer alguma ação em benefício do bem feito em favor dos demais. Aí é que o Papa Francisco profetiza contra a ideia do individualismo e a favor do ser relacional.

\footnotetext{
${ }^{6}$ Halík, 2016: 223 ss.

${ }^{7} \mathrm{Cf}$.<http://w2.vatican.va/content/francesco/pt/messages/pontmessages/2014/documents/papafrancesco 20140117 messaggio-wef-davos.html>

8 Disponível em:<w2.vatican.va/.../pt/letters/2013/documents/papa-francesco_20131110_prefazione-librobertone.html>. Acesso em: 26 de janeiro de 2018.
} 
O serviço da reflexão ética não pode ser reduzido a palavras e discursos, nem apenas a uma forma ideal de voluntariado, mas precisa ser uma escolha convincente e livre capaz de gerar os frutos de vínculos sociais comprometidos em fazer acontecer um amor capaz de construir uma humanidade nova, dinamizadora de processos de humanização, pelo modo renovado de viver e de considerar a originalidade de cada ser humano. O direito mais importante de uma pessoa não consiste em não ser impedido de realizar suas próprias aspirações, mas o de poder realizá-las de maneira efetiva e integral, contribuindo assim de modo pessoal à construção do bem comum.

Em palavras do Papa Francisco: "não é suficiente evitar a injustiça, se não se promove a

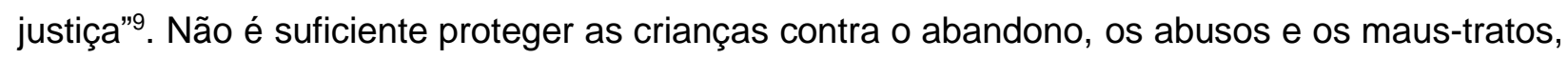
se não se educam os jovens a um amor pleno e gratuito pela existência humana nas suas diferentes fases, e se não se ajudam com a reflexão os variados grupos de famílias para que os recursos de que dispõem ou têm necessidade sejam compreendidos desde prioridades, e não pelo efeito aprisionador da propaganda com a intenção de conduzir ao consumo. Esta consciência não cresce espontaneamente, mas implica a necessidade de investir esforços, paciência, compromisso quotidiano, sinceridade, humildade e profissionalidade.

Fazendo uma breve incursão de 'leitura sensível' do que vem dizendo o Magistério do Papa Francisco, e comungando com o que nestes cinco anos é sugestivo em seu modo de "falar desde os gestos", como conduta condizente com uma ética cristã, é muito importante olhar com acurada atenção aos testemunhos que falam por si mesmos, independente das crenças diversificadas nas variadas culturas, e deter-nos em sua firmeza em denunciar e ser palavra de profecia em contra a injustiça.

O Papa nos motiva a que escolhamos a vida, e que pratiquemos um tipo de 'exílio' com relação a cultura individualista, incentivando-nos a que nos abstenhamos de toda e qualquer insinuação que colabore com a exploração, sustentando que hoje temos que dizer 'não' a uma cultura de exclusão e de iniquidade.

Assim como o mandamento de "não matar" põe um limite claro para assegurar o valor da vida humana, assim também hoje devemos dizer "não a uma economia da exclusão e de desigualdade social, porque esta economia mata (EG 53).

Já em outra época (1974), Dom Hélder Câmara afirmava categoricamente que nas operações destinadas a conseguir o máximo lucro, o custo humano não entra em considerações.

A crise mundial, que envolve as finanças e a economia, evidencia suas deformações, reduzindo o ser humano a uma única exigência que é a do consumo, fazendo com que ele próprio seja visto como um bem de consumo, que se pode usar e jogar fora chamada pelo Papa de 'cultura do descarte', do bota-fora. Em tal contexto, a solidariedade, que é o tesouro dos pobres e da humanidade, acaba por ser considerada contraria a racionalidade financeira e econômica.

\footnotetext{
${ }^{9}$ Em variadas alocuções e discursos às autoridades nos diversos âmbitos de suas visitas apostólicas.
} 
Enquanto os rendimentos de uma minoria crescem de maneira exponencial, os da maioria vão-se exaurindo. Este desequilíbrio promove a autonomia absoluta dos mercados e a especulação financeira, negando assim o direito de controle aos Estados, que têm precisamente a responsabilidade de prover o bem comum. E instaura-se uma nova tirania, invisível e às vezes virtual, que impõe unilateralmente suas leis e regras.

A avidez de poder e riqueza não conhecem limites, e por trás destas atitudes, escondese a recusa da ética que visa frear a manipulação e sujeição da pessoa às categorias do mercado; então o valor central do respeito para as relações humanas e humanizadora, é posto à margem gerando um sem número de carências nas relações. Desaparece o testemunho fazendo surgir um modo sutil da recusa de Deus pelo fato mesmo de não se afirmar a primazia e centralidade da dignidade de todo ser humano.

A ética então se torna um tema indiferente, porque dentro de uma hierarquia de valores na 'axiologia', o dinheiro deverá ocupar um lugar secundário frente a primazia do direito à vida e respeito à dignidade de todos. $\mathrm{E}$, será sempre oportuno e bem lembrado, que no interior de uma instituição cristã, a afirmação dos valores centrais de filiação e fraternidade, solidariedade e partilha, constitui assunto central no reconhecimento do direito dos filhos e filhas de Deus de ter vida em abundância (cf. João 10,10).

Chama-nos atenção o quanto cresce a incidência de deformações no humano, e o que gera viver sob a tirania do medo e da insegurança com os seus resultados de uma enorme quantidade de síndromes e patologias que vão diminuindo a alegria de viver; fazendo surgir o embrutecimento, imoralidade e violência cada vez maiores, legitimados pelos sistemas modernos das redes sociais, tornando sempre mais evidente a pobreza do humano, em processos de degradação de uma vida dignificante.

Neste contexto, Deus pode ser considerado como perigo porque chama o ser humano à sua plena realização e à independência de qualquer tipo de escravidão. A dimensão humana da ética permite criar um equilíbrio e uma ordem social mais humana, que faz recordar as palavras de São João Crisóstomo: "Não partilhar com os pobres os próprios bens é roubar-lhes a vida”, e ainda: "Os bens que possuímos não são nossos, mas deles" (Homilia sobre Lázaro 1, 6). O dinheiro deve servir, e não governar!

O amor é para todos, ricos e pobres; mas nos alerta o Papa o dever de recordar ao rico, em nome de Cristo e da irmandade, o dever de reconhecimento do pobre, de respeitá-lo e promovê-lo tratando-o com dignidade e diminuindo as distâncias que ao longo da história foram criadas entre uns e outros inviabilizando a construção de um 'nós' verdadeiramente humano e humanizador, que qualifica o Papa de "mística do nós", garantia de um testemunho de que quando afirmamos crer, nos comprometemos com o sonho 'utopia' em construir uma comunidade nova. Daí, a exortação do Papa à solidariedade desinteressada e ao retorno a uma ética que favoreça o ser humano em sua realidade financeira e econômica, social e cultural, inserindo todos no compromisso de realidades que garantam a vida do planeta. 
A Igreja, representada neste espaço da academia, não pode cessar de trabalhar pelo desenvolvimento integral de toda a pessoa. E neste sentido, recorda o Francisco que o bem comum não deveria ser simplesmente um acréscimo, um esquema conceitual de reduzido valor, inserido nos programas políticos de interesses privados. E, a lgreja tem o dever de encorajar aos que governam, a permanecerem verdadeiramente a serviço do bem comum, exortando aos dirigentes das realidades financeiras e a tomarem em sério a consideração que traz a ética na exigência da solidariedade.

Com a publicação da Constituição Apostólica Veritatis gaudium (Alegria da verdade) sobre as Universidades, o Papa Francisco insiste na 'utopia' do bem dizendo: "o homem é capaz de alcançar uma visão unitária e orgânica do saber, e esta é uma das tarefas que o pensamento cristão deverá assumir durante o próximo milênio cristão" ${ }^{10}$

"Deus, em Cristo, não redime somente a pessoa individual, mas também as relações sociais entre os homens" (Idem).

\section{Referência bibliográfica:}

- Exortação Apostólica Evangelii Gaudium do Papa Francisco, Paulinas, 2013.

- Constituição apostólica Veritatis gaudium do Papa Francisco.

- CUDA, Emilce: Para leer a Francisco. Teologia, ética y política. Buenos Aires. Manantial, 2016.

- Halík, Tomás: A noite do confessor. Petrópolis. Vozes, 2016.

- Site da Santa Sé: vatican.va

\section{Perguntas para o exercício da reflexão:}

1. Quais afirmações ou considerações do texto que evidenciam o proceder de uma ética cristã?

2. O que sugere a 'profecia' do Papa Francisco e suas exigências para mim? 